\title{
An unusual complication of stenosis of a colostomy
}

\author{
D.C. Haiart
}

The Northern Hospital, Cheetham Hill Road, Manchester 8, UK.

\begin{abstract}
Summary: A patient is reported in whom stenosis of the colostomy was responsible for perforation of the colostomy by a bone. Necrotizing gangrene of the abdominal wall developed. The management of the resulting full thickness defect of the abdominal wall is described.
\end{abstract}

\section{Introduction}

Stenosis is a common complication of end colostomies (Burns, 1970). It usually presents as dysfunction of the colostomy and may culminate in intestinal obstruction. The present case is one of stenosis of the colostomy which presented in an unusual way.

\section{Case report}

A 77 year old male, who had undergone abdominoperineal resection of a carcinoma of the rectum $7 y$ previously, presented with a 4 week history of weight loss, malaise and abdominal pain. This was maximal between his colostomy site and a large incisional hernia which protruded through his left paramedian incision.

On examination, he was edentulous but had a full set of false teeth. He was pyrexial and there was a tender mass at the site of his pain. The colostomy was stenosed and only admitted a finger tip. The mass was thought to be inflammatory and initially he was treated with intravenous fluids, gentamicin and metronidazole. Three days later the skin over the mass became red, hot and oedematous and he developed necrotizing gangrene of the skin covering the hernial sac.

At operation, the necrotic skin and part of the left rectus abdominis muscle, which was non-viable, was widely excised. The peritoneal cavity was uncontaminated but there were two large abscess cavities leading towards the colostomy. One lay between peritoneum and muscle and the other between muscle and skin. In the deeper cavity a $6 \mathrm{~cm}$ long sliver of bone was found. It was thought that the bone had impacted in the intramural terminal colon behind the narrowed stoma resulting in perforation of the bowel and paracolic abscess formation but no hole in the bowel could be

D.C. Haiart, F.R.C.S.

Accepted: 20 September 1974 demonstrated, despite inflating it by means of a sterile sigmoidoscope and filling the cavity with saline. The stenosed colostomy was refashioned by excising the distal $5 \mathrm{~cm}$ of colon without resiting it.

The full thickness defect of the abdominal wall was treated conservatively and allowed to heal by secondary intention. It was covered initially with paraffin gauze, wool and a binder. Within $4 \mathrm{~d}$ peritoneum had grown over the exposed bowel (Figure 1). The wound was then simply dressed with saline soaked gauze roll. Five weeks later skin cover was virtually complete (Figure 2) and the patient was discharged home to the care of the district nurse.

When seen 5 months after his operation he was well but still had a large incisional hernia which he controlled with an abdominal support. The skin remained completely healed and the colostomy was of normal calibre and functioning daily. He still could not remember eating anything which might have led to his illness.

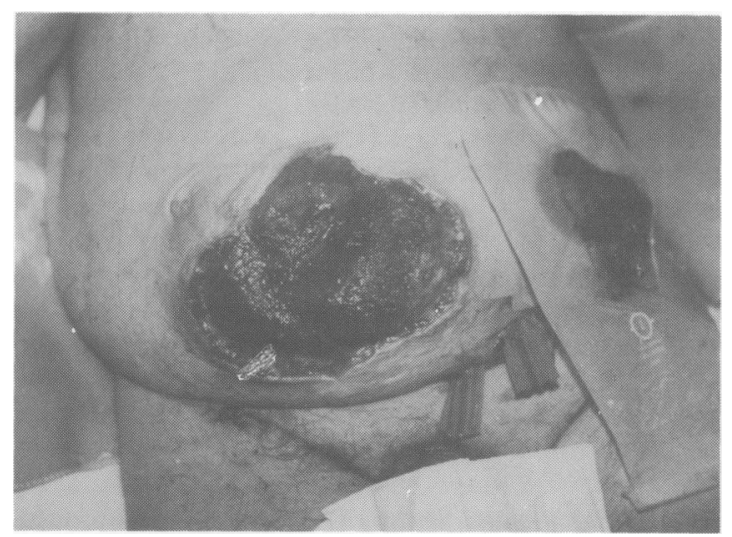

Figure 1 Four days after operation - peritoneum already covering the exposed bowel.

(C) The Fellowship of Postgraduate Medicine, 1985 


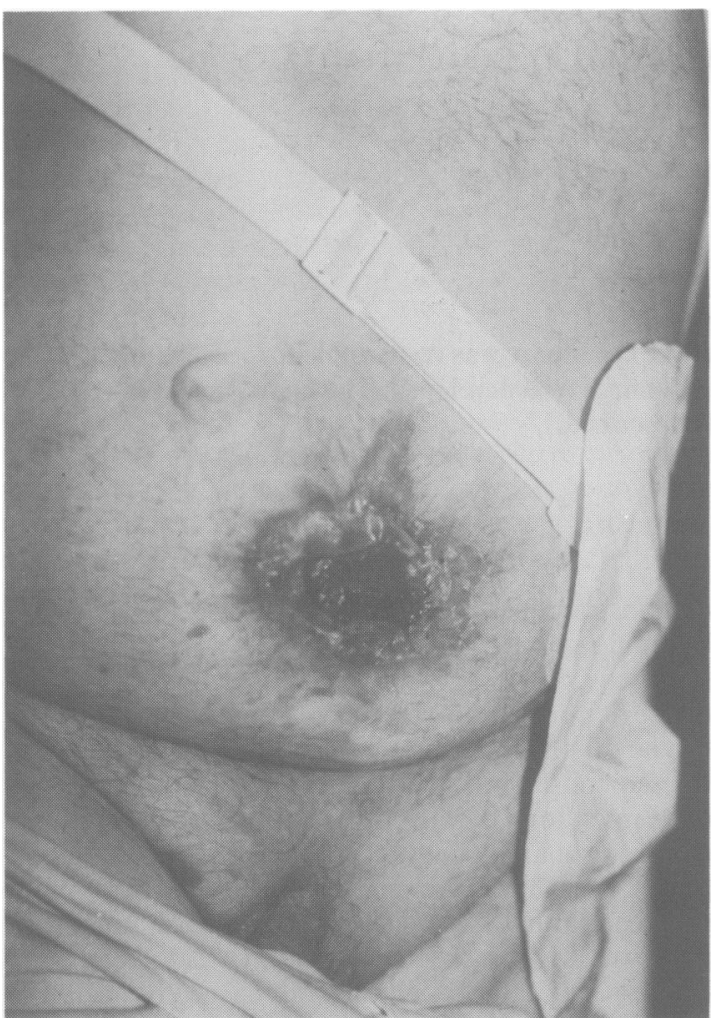

Figure 2 Five and a half weeks after operation - the defect in the abdominal wall virtually closed.

\section{References}

BUNKER, P.G. (1962). The role of dentistry in problems of foreign bodies in the air and food passages. Journal of the American Dental Association, 64, 782.

BURNS, F.J. (1970). Complications of colostomy. Diseases of the Colon and Rectum, 13, 448.

GREATOREX, R. \& SCOTT, I. (1984). Sigmoid colon perforation by a chicken wish bone. Gastroenterology in Practice, 6, 21.

HENDERSON, F.F. \& GASTON, E.A. (1938). Ingested foreign

\section{Discussion}

Stenosis of end colostomies accounts for about $41 \%$ of complications directly attributable to the colostomy itself (Burns, 1970). Ingestion of foreign bodies is more common in those who wear dentures due to decreased gingival and palatal sensitivity (Bunker, 1962). Only $1 \%$ of swallowed foreign bodies result in intestinal perforation (Henderson \& Gaston, 1938). Forty five $\%$ of perforations are due to animal bones, the ileo-caecal region being the commonest site (MacManus, 1941), no doubt due to the narrowness of the bowel at this point. The narrowing of the bowel due to stenosis of the colostomy explains the site of perforation in this case. A recent report of perforation of the sigmoid colon by a chicken wish bone attributes the site of perforation to underlying diverticular disease (Greatorex \& Scott, 1984) again possibly due to narrowing.

Perforation of a colostomy is well documented but is usually the result of instrumentation of the stoma from without, either during irrigation (Isa \& Quan, 1978) or, more rarely, at barium examination via the colostomy (Spiro \& Hertz, 1966). There is no previous report of colonic perforation by an ingested foreign body where stenosis of the colostomy played a significant part.

\section{Acknowledgements}

I would like to thank Mr R.J. Williams for permission to report this case. I would also like to thank Mr J.M.T. Howat for helpful advice in writing this article.

body in the gastrointestinal tract. Archives of Surgery, 36, 66.

ISA, S. \& QUAN, S.H. (1978). Colostomy perforation. Diseases of the Colon and Rectum, 21, 92.

MacMANUS, J.E. (1941). Perforations of the intestine by ingested foreign bodies. American Journal of Surgery, 53, 393.

SPIRO, R.H. \& HERTZ, R.E. (1966). Colostomy perforation. Surgery, 60, 590. 